\title{
Chemotaxonomic Analysis of the Venom Composition within the Ant Genus Strumigenys (Hymenoptera: Formicidae) in Taiwan
}

\author{
CH CHIEN, CC LIN
}

National Changhua University of Education, Changhua City, Taiwan

\section{Article History \\ Edited by \\ Evandro do Nascimento Silva, UEFS, Brazil \\ Received 12 March 2014 \\ Initial acceptance 22 May 2014 \\ Final acceptance 15 September 2014}

\section{Keywords}

Dacetine ants, SPME, venom, GC/MS

\section{Corresponding author}

Chung Chi Lin

Department of Biology

National Changhua University of

Education

500-01 Changhua, Taiwan

E-Mail: cclin@cc.ncue.edu.tw

\begin{abstract}
In Taiwan, the ant genus Strumigenys is represented by 13 species, nine of which being endemic to this island. Classic morphological taxonomy can be complex and may lead to equivoque identification within this group. To clarify subtle species assignments, we investigated the venom composition of five Strumigenys species, using SPME extraction and GC/MS analyses, and searched for a suitable chemical marker. Our results indicate that three out of the five species tested showed enough specificity in their chemical profiles to allow clear differentiation. However, the two remaining species could not be distinguished from each other on the basis of their venom composition. We further assessed the phylogenetic relationships between the five species, analyzing both morphological and chemical characters. Our clusters revealed congruency between some species associations and suggested that the analysis of venom composition may apply, at least partially, to Strumigenys chemosystematics. However, important discrepancies also appeared, signifying that selective pressures for chemical diversification have operated differentially during the speciation and dispersal processes within this genus in Taiwan.
\end{abstract}

\section{Introduction}

The myrmicine ant tribe Dacetini includes 9 genera and about 872 species largely distributed in the tropical and subtropical areas (Bolton, 2000). Dacetine ants are characterized by their pyriform head, their prey-seizure shaped mandibles and a singular spongiform tissue in the petiolar area (Bolton, 1999, 2000). Within the tribe, Strumigenys and Pyramica are the most speciose genera, containing $90 \%$ of total species (Bolton, 2000). In Taiwan, all the 27 species of dacetine ants belong to these two genera, but Strumigenys ants received comparatively more attention by authors, especially in regard to taxonomy and phylogeny (Lin \& Wu, 1998, 2001; Hung et al., 2004). Thirteen species of Strumigenys are present across the island, nine of which being endemic (Lin \& Wu, 1998, 2001). Like all Dacetini species, they are predators capturing small arthropods, mostly collembolans, by means of their specialized snap jaws (Brown \& Wilson, 1959;
Masuko, 1984). Colonies nest in rotten wood and under rocks of original or secondary forest litter. Personal observations (C.-C. Lin) indicate that they hardly contain more than 200 individuals in laboratory and that some species may be polygynous. However, because of their minute size and cryptic habits, field collections proved hazardous and some species are described from one specimen only (Lin, 1998; Lin \& Wu, 2001). Consequently, their biology and social organization remain poorly investigated.

In addition to these impediments, many Taiwanese Strumigenys species can display a great morphological resemblance, that can only be solved by subtle differences in the pilosity or other characters solely observed under electron microscope (Lin, 1998, and see hereafter). This makes their identification complex even for specialists and strongly hampers the conduct of sound experimental studies. In ants, chemical analyses of the diverse exocrine secretions can be a valuable addition to the use of morphological characters to help for 
accurate species assignments. For instance, diagnostic suites of compounds have been identified in the secretions of the mandibular, postpharyngeal and Dufour glands within the formicine ant genus Cataglyphis (Keegans et al., 1992; Hefetz \& Lenoir, 1992; Dahbi et al., 1996, 2008) and their specificity allowed the assessment of phylogenetic relationships that were in agreement with morphological data. In a same way, venom chemical composition also revealed its diagnostic power within the fire ants complex. Similar Solenopsis species and their hybrids can be accurately identified through their characteristic amounts of various 2,6-dialkyl piperidine (Brand et al., 1973a,b; Vander Meer et al., 1985; Vander Meer and Lofgren, 1990; Dall'Aglio-Holvorcem et al., 2009) and $\Delta^{1,6_{-}}$ piperideine alkaloids (Chen et al., 2010). More generally, an important diversification of both the function and chemistry of the venom has occurred in ants, which provides interesting material for chemotaxonomic analyses (Hefetz, 1993).

As part of our ongoing taxonomic investigation of the genus Strumigenys in Taiwan (Lin, 1993, 1998; Lin \& Wu, 2001), the composition of worker venom was investigated through GC/MS analyses in order to identify specific chemical markers for five species. We also assessed their phylogenetic relationships using classical taxonomy and finally compared the results obtained from both morphological and chemical analyses to evaluate the usefulness of our method for Strumigenys chemosystematics.

\section{Materials and methods}

\section{Ant collection and laboratory conditions}

Colonies of Strumigenys ants belonging to five species (S. chuchihensis, S. formosensis, S. liukueiensis, S. minutula and $S$. solifontis, respectively) were collected at four different localities in Taiwan (Table 1, Fig 1) by hand searching. Each colony contained about 50 150 workers, together with some developing brood and at least one queen. In the laboratory, they were reared in plastered nest, covered by a red plastic plate and kept at $25^{\circ} \mathrm{C}, 60 \% \mathrm{RH}$ and a $13 / 11 \mathrm{LD}$ photoperiod. They were fed every three days with collembolans, and water was provided ad libitum.

Table 1. Summary of the respective dates and locales of collections for the five Strumigenys species ( $c f$. Fig 1 for details of Taiwan geography).

\begin{tabular}{lccc}
\hline \multicolumn{1}{c}{ Species } & Locale & Collection time & Colonies \\
\hline S. chuchihensis & 1 & $2009 / 2011$ & $1 / 1$ \\
S. minutula & 2 & 2009 & 5 \\
S. formosensis & 2 & 2009 & 6 \\
S. liukueiensis & 3 & $2008 / 2011$ & $1 / 3$ \\
S. solifontis & 4 & 2009 & 3 \\
\hline
\end{tabular}

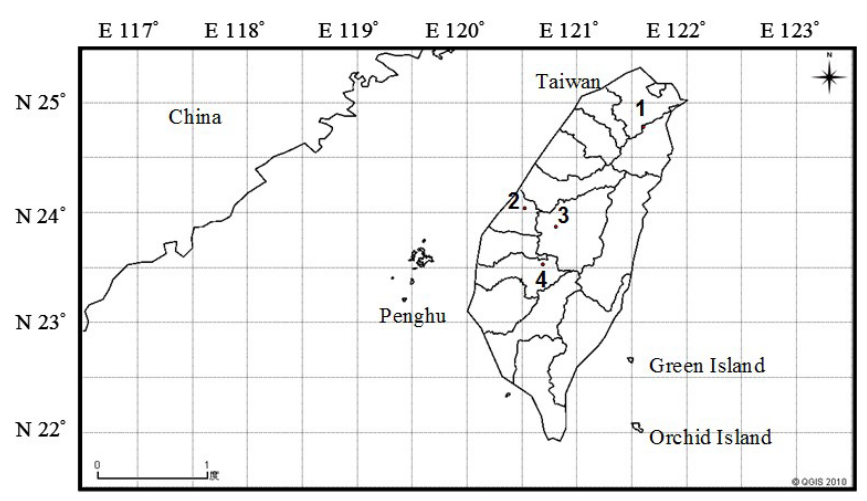

Fig 1. Collecting sites of Strumigenys ants. 1: Fushan, Ilan County; 2: Pakuashan, Changhua City; 3: Chichi, Nantou County; 4: Shuisheliao, Chiai County.

\section{Morphological characters state definition}

The characters state definition and polarities used in this study largely followed prevailing theories of evolutionary change within the tribe Dacetini (Brown \& Wilson, 1959; Baroni Urbani \& de Andrade, 1994; Bolton, 1999, 2000). The characters and character state codes used in the cladistic analysis are defined in Table 2. Characters include both those with simple binary state and multistate characters. All multistate characters were treated as unordered. If more than one state was present for a given taxon, the character was recorded as ' $0 \& 1$ ' (meaning that the taxon had state 0 and 1 ). These characters were not weighted in the analysis.

\section{Chemical analysis}

Solid-Phase-Microextraction (SPME). When applied to physically tiny ants, the chemotaxonomic techniques traditionally used to analyze their cuticular hydrocarbons or exocrine glands secretions require the dissection or sacrifice of dozens of workers, which may hamper any further laboratory experiments on the small and rare colonies of Strumigenys. Instead, we sampled the venom secreted by workers that were kept alive, using a $7 \mu \mathrm{m}$ layer polydimethylsiloxane (PDMS) fiber (Supelco, Sigma-Aldrich, St Louis, MO, USA). Ants were initially immobilized on a special device made of foam (Fig 2). When their abdomen is stimulated, Strumigenys workers protrude their sting and droplets of venom stand out. The SPME fiber was carefully thrust into the droplets to collect the venom. For each sample, we pooled the venom from three different

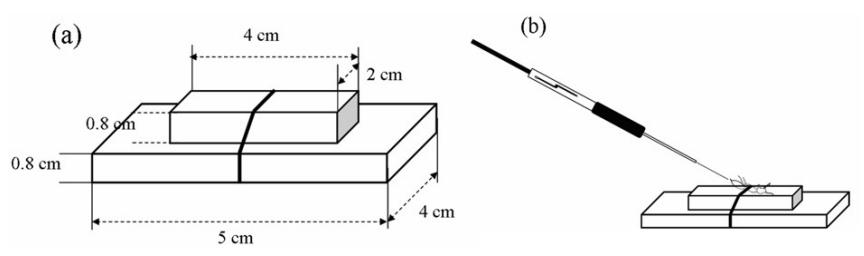

Fig 2. Device used for ant immobilization (a) before SPME venom extraction (b). 
Table 2 Morphological characters and their states used for the phylogenetic analysis of the genus Strumigenys. (Q: queen, W: worker).

1. Number of teeth or denticles of apical fork of mandible (W, Q): (0) 4; (1) 3; (2) 6.

2. Preapical teeth of mandible (W, $Q)$ : (0) spiniform; (1) reduced.

3. Mandible shape (W, Q): (0) hook like; (1) sickle like.

4. Anterior clypeal margin (W, Q): (0) transverse; (1) deeply concave medially.

5. Long flagellate hair on margin of antennal acrobe $(W, Q)$ : (0) absent; (1) present.

6. Flagellate hair on genae (W, Q): (0) absent; (1) present.

7. A row of erect hairs on occiput $(W, Q)$ : (0) absent; (1) present.

8. Pilosity type of carnium (W, Q): (0) spatulate ; (1) erect; (2) flagellate; (3) spoon-shaped

9. Hair on pronotal humeli (W): (0) absent; (1) flagellate; (2) erect; (3) columnar.

10. Lateral marginal hair on mesonotum (W): (0) absent; (1) flagellate; (2) erect; (3) columnar.

11. Flocculus hairs on pronotum (W): (0) absent; (1) sparse; (2) numerous.

12. Sculpture on mesopleuron (W): (0) absent; (1) present.

13. Sculpture on propodeum (W): (0) smooth; (1) microreticulate; (2) lacunous.

14. Propodeal teeth (W, Q): (0) well developed; (1) sub-spongiform ; (2) spongiform.

15. Pilosity type on pedicel (W, Q): (0) spatulate ; (1) erect; (2) flagellate; (3) spoon-shaped

16. Density of hairs on fourth abdominal tergum (W, Q): (0) sparse; (1) numerous.

17. Mandiblular index, $\mathrm{MI}(\mathrm{Q}, \mathrm{W})$ : (0) $\mathrm{MI}>40$; (1) $\mathrm{MI}<40$.

18. Number of ommatidia (W): (0) > 10; (1) $6 \sim 10$; $(2)<6$.

19. Ocellus (Q): (0) large; (1) small.

20. Mesonotum (Q): (0) convex; (1) even.

21. Pilosity type on tergum of gaster (W, Q): (0) erect; (1) flagellate; (2) columnar; (3) spoon-shaped.

22. Sculpture on lateral surfaces of pronotum (W): (0) smooth; (1) sculpture on part; (2) sculpture presnet on all.

23. Total body length, $\mathrm{TL}(\mathrm{W}):(0)>3 \mathrm{~mm}$; (1) $2 \mathrm{~mm} \sim 3 \mathrm{~mm}$; (2) $<2 \mathrm{~mm}$.

individuals. The SPME fiber was then immediately desorbed in the injection port of a gas chromatograph. Three samples were performed for each colony.

GC/MS analyzes. Venom composition was analyzed on a Varian GC 3800 gas chromatograph coupled with Varian Saturn 2200 turbo mass (operating at $70 \mathrm{eV}$, former Varian Inc. now Agilent, Palo Alto, Ca, USA). The GC/MS was fitted with a VF-5ms 5\% phenyl 95\% dimethylpolysiloxane capillary column (30 m x $0.25 \mathrm{~mm}$ ). Helium (purity 99.995\%) was used as the carrier gas at $1.0 \mathrm{ml} / \mathrm{min}$ flow rate. The SPME fiber was directly inserted into the injection port of gas chromatograph which was set at $250^{\circ} \mathrm{C}$ in split/splitless mode. The venom samples were run using the following temperature program from $120^{\circ} \mathrm{C}$ (5 min. initial hold) to $180^{\circ} \mathrm{C}$ at $10^{\circ} \mathrm{C}$ $\min ^{-1}\left(3 \mathrm{~min}\right.$. intermediate hold), then to $240^{\circ} \mathrm{C}$ at $10^{\circ} \mathrm{Cmin}^{-}$ ${ }^{1}$ (10 min. second intermediate hold), and finally to $280^{\circ} \mathrm{C}$ at $5^{\circ} \mathrm{Cmin}^{-1}$ (6 min. final hold). The standard of the series n-alkane $\left(\mathrm{C}_{10} \sim \mathrm{C}_{22}\right)$ was used to determine retention indexes
(RI) (Kováts, 1965). Our objective in this study was to compare the chemical profiles of the five Strumigenys species, not to provide absolute identifications of all of the different compounds that were found.

\section{Statistical analysis}

All total ion chromatograms were processed through the MS Workstation 6.9 (Varian Inc.). Differences in the chemical profiles were assessed using principle component analysis (PCA) for all peaks integrated. Morphological and chemical patterns of the different species were further analyzed on separate clusters obtained from the respective coefficient of correlation matrices (Single-link method, 1-Pearson r). For the analysis, each chromatogram was divided into three sections while assigning a value to each peak according to its relative area $(\mathrm{RA}=$ target peak area / total peak area): peaks ranging from 0 to $10 \%, 10-50 \%$, and $>50 \%$ were assigned values of $1-3$, respectively (modified from Dahbi et al., 1996). All statistics were performed with Statistica 7 (StatSoft Inc., Tulsa, OK, USA).

\section{Results}

\section{Morphological study}

The status of the characters for the various Strumigenys species and the ensuing cluster analysis (Fig 3) revealed three assemblies of species. A first clade includes the two species $S$. liukueiensis and S. solifontis. A second clade is composed of the two species $S$. chuchihensis and $S$. minutula. Finally, placed at the root of the clustering, $S$.formosensis appears distinct from the other four species. Our results match those obtained by Lin (1998), who, analyzing a total 12 Taiwanese and 5 Japanese Strumigenys ants, also classified these five species in three different groups, but in a slightly different way: the two species S. solifontis and S. liukueiensis were identically

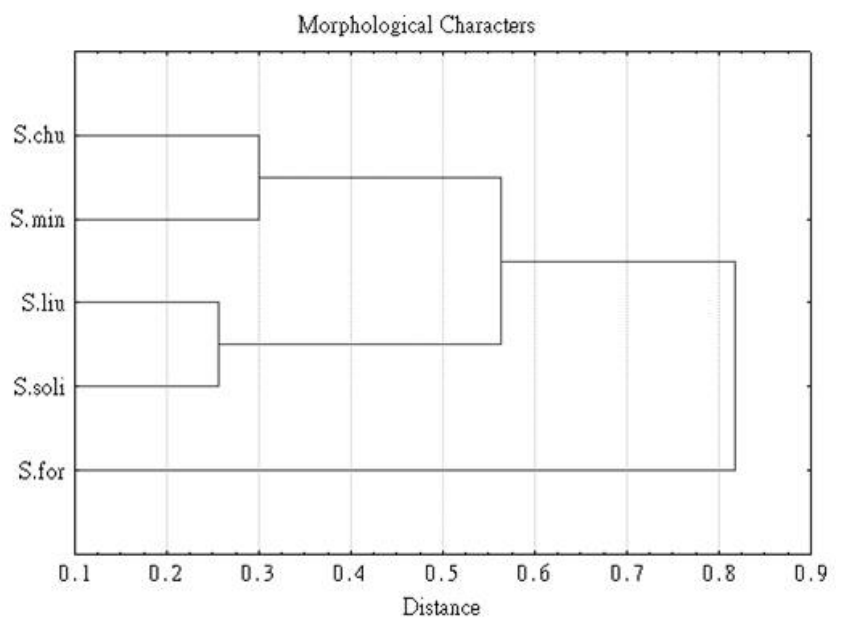

Fig 3. Cluster analysis based on the morphological characters. (Single link, 1-Pearson r). (S.for: S. formosensis; S.min: S. minutula; S.chu: S. chuchihensis; S.liu: S. liukueiensis; S.soli: S. solifontis). 
clustered in a same solifontis group, confirming their close phylogenetic relation, whereas $S$. chuchihensis was included in their sister lewisi group. However, S. formosensis and $S$. minutula were both integrated in a distinct "tropical" group of Strumigenys ants. Later, in their description of the newlydiscovered S. chuchihensis, Lin \& Wu (2001) finally considered this species closely related to those of the godeffroyi group, which includes, among others, S. minutula, S. solifontis and S. luikueiensis while $S$. formosensis was included in the mayri sister group of Strumigenys species (Bolton, 2000).

\section{Chemical study}

For the five Strumigenys species, a total of 16 constituents were detected in our chemical analysis of the workers venom composition (Fig 4). According to their respective retention index and spectrum (Table 3), we suggest that these compounds may be terpenes (and more precisely sesquiterpenes for most of them) but this will need furtheranalyses to be clearly confirmed. Nevertheless, they were present in sufficient quantities in our samples to allow for a comparison between species. Despite important similarities as for the number and identity of constituents, as well as for the presence of a major peak ( $\mathrm{RA}>50 \%)$ in all chemical profiles, some qualitative and quantitative differences between species were nonetheless revealed. First, none of each 16 compounds were commonly present in all venoms. In particular, the identity of the major constituents varies across the different profiles. The

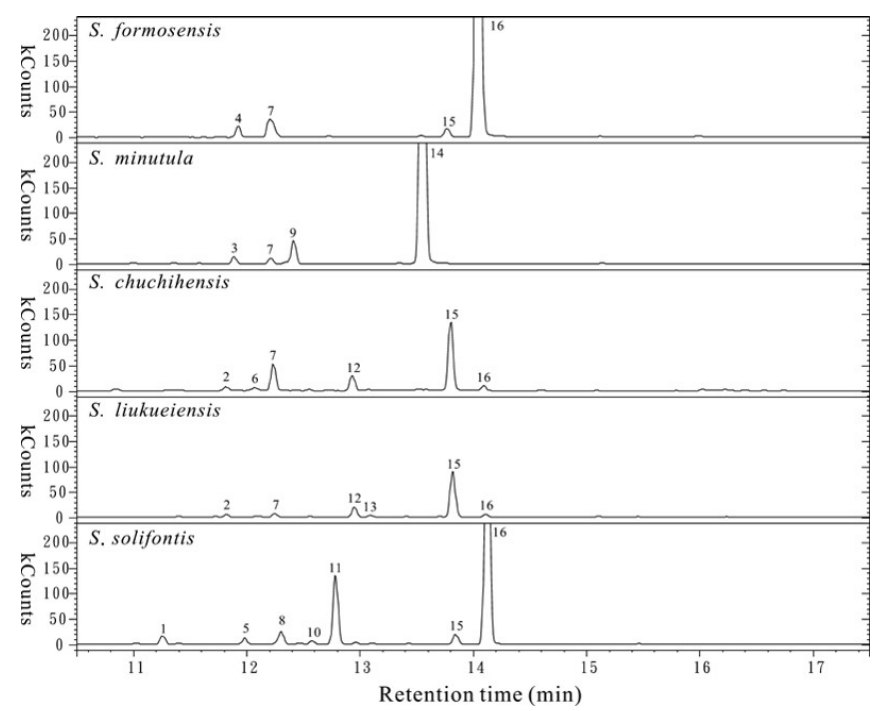

Fig 4. Gas chromatograms of venom revealing 16 different compounds across the five Strumigenys species.

same is true concerning their respective abundance, ranging from $53.60 \%$ to $93.61 \%$ respectively (Table 3 ). The PCA illustrates the relative specificity of the various venom compositions (Fig 5). Three species present clearly distinct profiles. Venom in S. minutula is mainly characterized by its major constituent (peak 14, absent in all other profiles), while $S$. formosensis and $S$. solifontis venoms share the same major compounds (peak 16) but in different proportions (Table 3). These two species are further separated on the basis of their secondary constituents (peaks 7 and 11, respectively). The PCA analysis also shows that the chemical composition of the workers venom appears relatively constant for each of these three species. In comparison, the venoms of the two remaining species, S. liukueiensis and S. chuchihensis, show a distinct composition, but our chemical analysis was insufficient to distinguish them from each other. They both share the same major compound (peak 15), in similar proportions, and present several minor constituents in common.

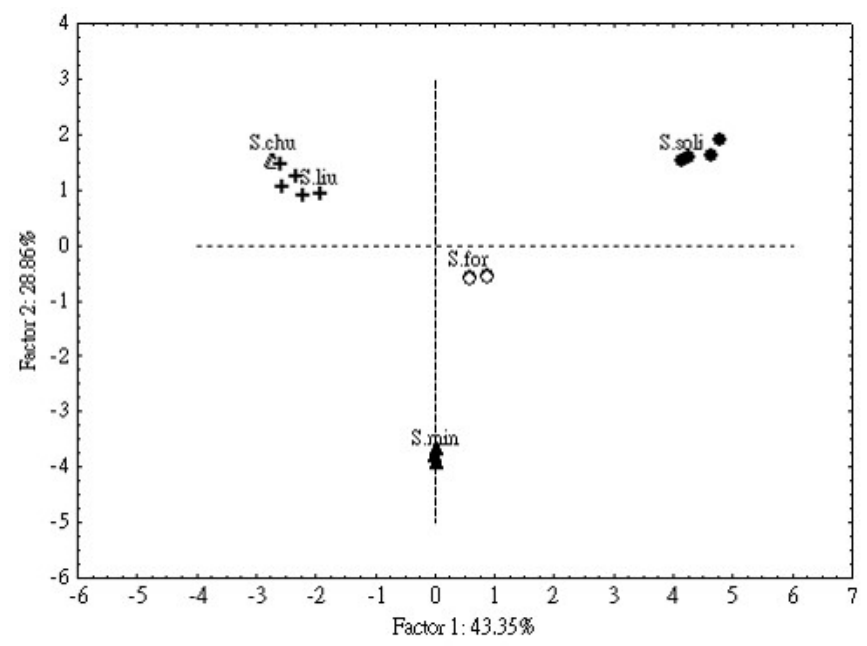

Fig 5. PCA analysis based on the peaks' relative areas (RAs) $(\bigcirc: S$. formosensis; : S. solifontis; $\mathbf{\Delta}$ : S. minutula; $\triangle$ : S. chuchihensis; +: S. liukueiensis ).

The result of the cluster analysis using the assigned values for all integrated peaks is shown in Fig 6. As in the morphological analysis (Fig 3), three clades were revealed, but important discrepancies in their respective composition appeared. S. formosensis was clustered with S. solifontis, while S. chuchihensis and S. liukueiensis were associated, S. minutula being clearly distinguished from the other four species.

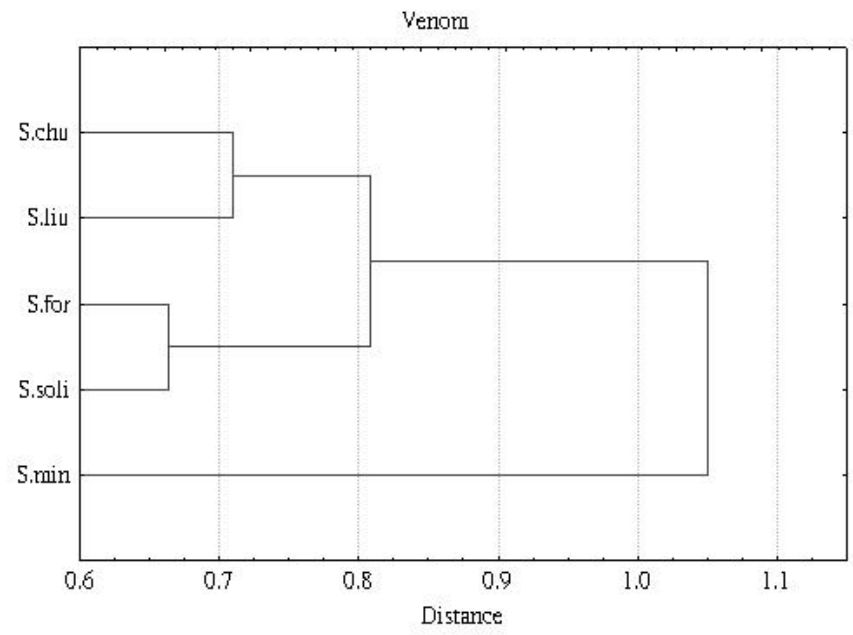

Fig 6. Cluster analysis based on the chemical characters. (Single link, 1-Pearson r). (S.for: S. formosensis; S.min: S. minutula; S.chu: S. chuchihensis; S.liu: S. liukueiensis; S.soli: S. solifontis). 


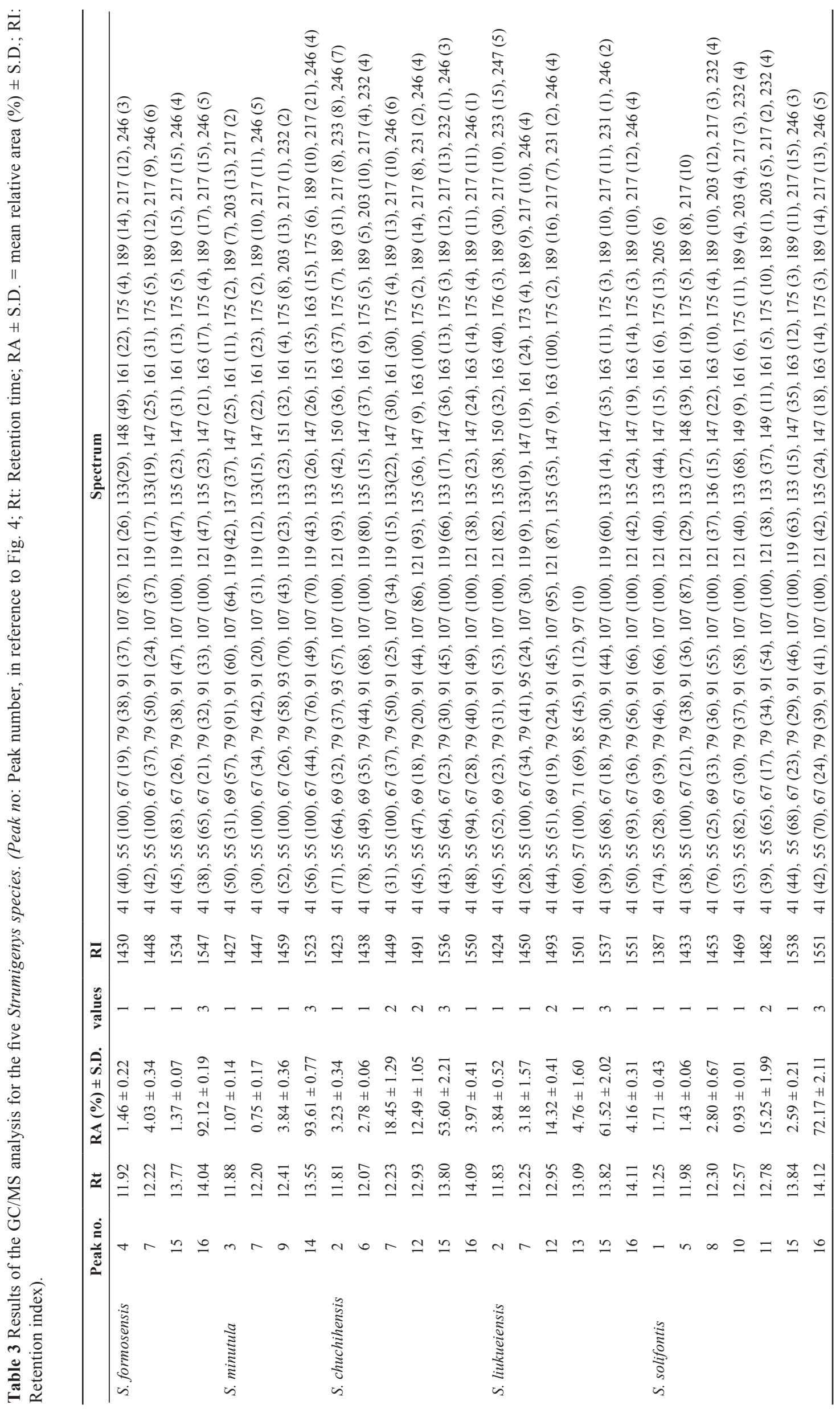




\section{Discussion}

Taiwan relative geographic isolation and mountainous relief led to the development of an important endemism within its ant fauna (Forel, 1912; Terayama \& Kubota, 1989; Lin, 1993, 1998). For instance, among Dacetine ants, nine out of 13 species of Strumigenys are only found on this island or surrounding islets. The present study aimed at providing a suitable chemical marker to elucidate subtle species assignments within this genus.

For this purpose, we analyzed the venom composition of Strumigenys workers that were maintained alive during the extraction process. We directly sampled droplets oozing from their extruded stings, which, as a result, contained a mixture of poison and Dufour glands secretions. The GC/MS analysis suggested that most of the compounds revealed are terpenes, which are frequent constituents of ant exocrine secretions, often present in Dufour gland (Francke \& Schulz, 2010; Morgan, 2008). The functions of Dufour secretions are diverse and only fragmentarily understood but when experiments have been conducted, they revealed to act as semiochemicals rather than noxious secretions used for predation or colony defense (Billen \& Morgan, 1998; Morgan, 2008). In some species, they can be the medium for the trail pheromone (Ritter et al., 1977; Vander Meer et al., 1981, 1988; Alvarez et al., 1987), or used to mark a territory or delimit a home range (Attygalle et al., 1983a,b). In others, the Dufour gland can be the source of alarm and/ or propaganda substances (Daloze et al., 1991; Ruano et al., 2005). Conversely to noxious secretions, these communicative chemicals are usually species-specific in their composition, hence subjected to selective pressures to diversify (Hefetz, 1993).

Interestingly, our chemical analysis revealed that the venom of Strumigenys workers offers diagnostic suites of constituents, at least for some species. Three out of the five species used in this study ( $S$. minutula, $S$. formosensis and $S$. solifontis) could be clearly separated in the PCA analysis. They showed sufficient differences, both in the identity and relative abundance of their main compounds, to permit unambiguous species assignment. However, the remaining two species ( $S$. chuchihensis and S. liukueiensis) presented similar chemical profiles and could not be distinguished on the basis of their venom composition. Alternately, chemical convergence in exocrine secretions might occur when species share identical ecological conditions. More likely however, similar venom composition may reflect a lack of selective pressure for chemical diversification between sister species (Hefetz, 1993; Dahbi et al., 1996).

In an attempt to clarify the situation, we assessed the phylogenetic relationships among the five Strumigenys species. Results of our morphological analysis are in agreement with those of earlier cladistic studies (Lin, 1993, 1998; Lin \& Wu, 2001; Bolton, 1999, 2000), confirming the phylogenetic proximity between $S$. chuchihensis, S. liukueiensis, S. minutula and $S$. solifontis. We thus support the view that these four species may belong to the same "godeffroyi" group, whereas
S. formosensis appears rather different and should reasonably be considered as member of the distinct "mayri" group. These species associations are further supported by genetic analysis. Hung et al. (2004) compared the size of internal transcribed spacer2(ITS2)rDNAsequences to investigate the phylogenetic relationships within Strumigenys ants in Taiwan and Japan. Their results indicated that $S$. chuchihensis, $S$. minutula and $S$. solifontis belonged to a same clade, while $S$. formosensis was included into a distinct, monophyletic group, together with other species endemic to Taiwan or surrounding islets. Importantly, for this study S. chuchihensis and S. liukueiensis were sampled in distant locales, respectively in the northern and central part of Taiwan (Fig 1). Previous collections concur to suggest that both endemic species occur in distinct areas and, altogether, evoke an allopatric speciation process between these two sister species (Lin, 1993, 1998). Were this hypothesis to be confirmed by additional biogeographic studies, the absence of ecological competition could imply a lack of any selective pressure to diversify their Dufour gland secretions. The great similarity in their chemical profiles might therefore reflect the ancestral composition within the "godeffroyi" group. This suggestion should be further tested on other semiochemicals, in particular cuticular hydrocarbons which are involved in nestmate recognition.

A significant discrepancy between our two clusters concerns the chemical separation of $S$. minutula from the three other species of the "godeffroyi" group. In the same time $S$. formosensis, though morphologically distinct, became closely associated with $S$. solifontis, and, at a lesser degree, with the two remaining "godeffroyi" species. This important shift in species arrangements strongly suggests that ecological constraints have shaped the composition of Dufour secretions in these Strumigenys ants during their dispersal in Taiwan (Hefetz, 1993; Dahbi et al., 1996). Indeed, conversely to S. chuchihensis and $S$. liukueiensis, the three other species show a broader geographic repartition and can occur sympatrically on Taiwan Main Island (Lin, 1998). Given their overlapping distributions and similar ecological niches, these closely related species have to maintain distinct exocrine compositions to preserve strict behavioral barriers, as illustrated by the PCA analysis of the venom profiles. Nevertheless, our understanding of the biogeographic history of Strumigenys ants in Taiwan is too fragmented to allow deducing the ancestral venom composition from these five chemical profiles, and further inferring the way they diversified. For instance, three species used in the present study are endemic to Taiwan but belong to separate clades (S. chuchihensis and S. liukueiensis on one hand and S. formosensis on the other hand) and consequently do not share direct common ancestor. This provides interesting material to investigate the origin, dispersal, speciation and extinction processes within this genus in Taiwan. From then on, it will be possible to speculate about the putative ancestral Dufour composition and clarify the implications of our results in Strumigenys chemosystematics. 
Finally, chemical analyses of workers venom secretions revealed to be a complementary but limited addition to the use of morphological characters for Strumigenys taxonomy in Taiwan. More experiments are needed to explore and compare the usefulness of other glandular secretions as phylogenetic indicators.

\section{References}

Alvarez, F.M., Vander Meer, R.K. \& Lofgren, C.S. (1987). Synthesis of homofarnesenes: trail pheromone components of the fire ant, Solenopsis invicta. Tetrahedron Letters, 43: 28972900 .

Attygalle, A.B., Cammaerts, M.C. \& Morgan, E.D. (1983a). Dufour gland secretion of Myrmica rugulosa and Myrmica schencki workers. Journal of Insect Physiology, 29: 27-32.

Attygalle, A.B., Evershed, R.P., Morgan, E.D. \& Cammaerts, M. (1983b). Dufour gland secretions of workers of the ants Myrmica sulcinodis and Myrmica lobicornis, and comparison with six other species of Myrmica. Insect Biochemistry, 13: 507-512.

Baroni Urbani, C. \& de Andrade, M.L. 1994. First description of fossil Dacetini ants with a critical analysis of the current classification of the tribe (amber collection Stuttgart: Hymenoptera, Formicidae. VI: Dacetini). Stuttgarter Beiträge zur Naturkunde Serie B, 198: 1-65.

Billen, J. \& Morgan, E.D. (1998). Pheromone communication in social insects: sources and secretions. In R.K. Vander Meer, M.D. Breed, K.E. Espelie, M.L. Winston (Eds.), Pheromone Communication in Social Insects (pp 3-33). Westview Press.

Bolton, B.(1999). Ant genera of the tribe Dacetonini(Hymenoptera: Formicidae). Journal of Natural History, 33: 1639-1689.

Bolton, B. (2000). The ant tribe Dacetini. Memoirs of the American Entomological Institute, 65: 1-1028.

Brand, J.M., Blum, M.S. \& Barlin, M.R. (1973a). Fire ant venoms: intraspecific and interspecific variation among castes and individuals. Toxicon, 11:325-331.

Brand, J.M., Blum, M.S. \& Ross, H.H. (1973b). Biochemical evolution in fire ant venoms. Insect Biochemistry, 3: 45-51.

Brown, W.L. \& Wilson, E.O. (1959). The evolution of the Dacetine ants. Quarterly Reviews of Biology, 34: 278-294.

Chen, J., Shang, H. \& Jin, X. (2010). Interspecific variation of $\Delta^{1,6}$-piperideine in imported fire ants. Toxicon, 55: 1181-1187.

Cruz-López, L., Jackson, B.D., Hefetz, A. \& Morgan, E.D. (2006). Alkaloids in the venom of Messor ants. Biochemistry, Systematics and Ecology, 34: 199-204.

Dahbi, A., Lenoir, A., Tinaut, A., Taghizadeh, T., Francke, W. \& Hefetz, A. (1996). Chemistry of the postpharyngeal gland secretion and its implication for the phylogeny of Iberian Cataglyphis species (Hymenoptera: Formicidae). Chemoecology, 7: 163-171.

Dahbi, A., Hefetz, A. \& Lenoir, A. (2008). Chemotaxonomy of some Cataglyphis ants from Morocco and Burkina Faso. Biochemistry, Systematics and Ecology, 36: 564-572.

Dall'Aglio-Holvorcem, C.G., Benson, W.W., Gilbert, L.E., Trager, J.C. \& Trigo, J.R. (2009). Chemical tools to distinguish the fire ant species Solenopsis invicta and S. saevissima (Formicidae: Myrmicinae) in Southeast Brazil. Biochemistry, Systematics and Ecology, 37: 442-451.

Daloze, D., Kaisin, M., Detrain, C. \& Pasteels, J.M. (1991). Chemical defenses in the three European species of Crematogaster ants. Cellular and Molecular Life Sciences, 47: 1082-1089.

Forel, A. (1912). H. Sauter's Formosa-Ausbeute: Formicidae (Hymenoptera). Entomologische Mitteilungen, 1: 45-81

Francke, W. \& Schulz, S. (2010). Pheromones of Terrestrial Invertebrates. In: L. Mander \& H.W. Lui(Eds.), Comprehensive Natural Products II. Chemistry and Biology (pp. 153-223). Oxford, Press.

Hefetz, A. \& Lenoir, A. (1992). Dufour's gland composition in the desert ant Cataglyphis: species specificity and population differences. Zeitschrift für Naturforschung C - A Journal of Biosciences, 47: 285-289.

Hefetz, A. (1993). Hymenopteran exocrine secretions as a tool for chemosystematic analysis: possibilities and constrains. Biochemistry, Systematics and Ecology, 21: 163-169.

Hung, Y.T., Chen, C.A., Wu, W.J., Lin, C.C. \& Shih, C.J. (2004). Phylogenetic utility of the ribosomal internal transcribed spacer 2 in Strumigenys spp. (Hymenoptera: Formicidae). Molecular Phylogenetics and Evolution, 32: 407-415.

Keegans, S., Morgan, E.D., Agosti, D. \& Wehner, R. (1992). What do glands tell us about species? A chemical case study of Cataglyphis ants. Biochemistry, Systematics and Ecology, 20: 559-572.

Kováts, E. (1965). Gas chromatographic comparison of organic substances in the retention index system. Advances in Chromatography, 1: 229-247.

Lin, C.C. (1993). Morphological and systematic studies on the Dacetine ants in Taiwan (Hymenoptera: Formicidae). Master Dissertation, National Taiwan University Press, Taiwan. 198 p.

Lin, C.C. (1998). Systematic and zoogeographic studies on the ant subfamily Myrmicinae in Taiwan (Hymenoptera: Formicidae). Ph.D. Dissertation, National Taiwan University Press, Taiwan. 748 p.

Lin, C.C. \& Wu, W.J. (2001). Three new species of Strumigenys Fr. Smith (Hymenoptera: Formicidae) with a key to Taiwanese species. Formosan Entomology, 21: 157-170.

Masuko, K. (1984). Studies on the predatory biology of oriental Dacetine ants (Hymenoptera: Formicidae) I. some japanese species of Stumigenys, Pentastruma and Epitritus, and a Malaysian Labidogenys, with special reference to hunting tactics in shortmandibulate forms. Insectes Sociaux, 31: 429-451. 
Morgan,E.D. (2008). Chemical sorcery for sociality: exocrine secretions of ants (Hymenoptera: Formicidae). Myrmecological News, 11: $79-90$.

Ritter, F.J., Bruggemann-Rotgans, I.E.M., Verwiel, P.E.J., Persoons, C.J. \& Talman, E. (1977). Trail pheromone of the pharaoh's ant, Monomorium pharaonis: isolation and identification of faranal, a terpenoid related to juvenile hormone II. Tetrahedron Letters 30: 2617-2618.

Ruano, F., Hefetz, A., Lenoir, A., Francke, W. \& Tinaut, A. (2005). Dufour's gland secretion as a repellent used during usurpation by slave-maker ant Rossomyrmex minuchae. Journal of Insect Physiology, 51: 1158-1164.

Terayama, M. \& Kubota, S. (1989). The ant tribe Dacetini (Hymenoptera, Formicidae) of Taiwan, with descriptions of three new species. Japanese Journal of Entomology, 57: 778-792.
Vander Meer, R.K., Williams, F.D. \& Lofgren, C.S. (1981). Hydrocarbon components of the trail pheromone of the red imported fire ant Solenopsis invicta. Tetrahedron Letters, 22: 1651-1654.

Vander Meer, R.K., Lofgren, C.S. \& Alvarez, F.M. (1985). Biochemical evidence for hybridization in fire ants. Florida Entomologist, 68: 501-506

Vander Meer, R.K., Alvarez, F. \& Lofgren, C.S. (1988). Isolation of the trail recruitment pheromone of Solenopsis invicta. Journal of Chemical Ecology, 14: 825-838.

Vander Meer, R.K. \& Lofgren, C.S. (1990). Chemotaxonomy applied to fire ant systematics in the United States and South America. In R.K. Vander Meer, K. Jaffe \& A.Cedeno(Eds.), Applied Myrmecology: A World Perspective (pp. 75-84). Westview Press.

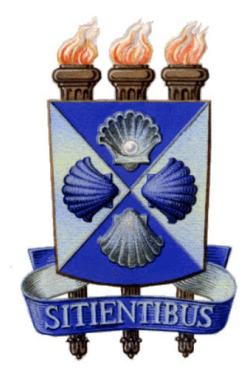

